\title{
EFEITO DO EXTRATO AQUOSO DA HYPTIS PECTINATA SOBRE A PROLIFERAÇÃO DE HEPATÓCITOS APÓS HEPATECTOMIA PARCIAL ${ }^{1}$
}

\author{
EFFECT OF THE AQUEOUS EXTRACT OF HYPTIS PECTINATA ON \\ HEPATOCYTE PROLIFERATION AFTER PARTIAL HEPATECTOMY
}

\author{
Renata Lemos Silva ${ }^{2}$ \\ Gustavo Barreto de Melo ${ }^{3}$ \\ Ângelo Roberto Antoniolli ${ }^{4}$ \\ Sônia Oliveira Lima ${ }^{4}$ \\ Valdinaldo Aragão de Melo ${ }^{4}$ \\ Fernando S. Ramalho ${ }^{5}$ \\ Leandra N.Z.Ramalho ${ }^{5}$ \\ Sérgio Zucoloto ${ }^{6}$ \\ Orlando de Castro e Silva Júnior ${ }^{7}$
}

\section{RESUMO}

Objetivo - O uso de plantas medicinais tem aumentado mundialmente. Então, é necessário saber seus possíveis efeitos a fim de estabelecer seu uso correto em seres humanos. Dessa forma, neste trabalho se propôs a estudar os efeitos do extrato aquoso das folhas da Hyptis pectinata, popularmente conhecida como "sambacaitá" ou "canudinho", sobre a regeneração hepática após hepatectomia parcial em ratos. Métodos - Dez ratos foram divididos em 2 grupos: grupos HP, que foi submetido à hepatectomia de $67 \%$ após 4 dias de administração de água destilada; e o grupo HP100, que foi submetido à hepatectomia parcial e administração oral de $100 \mathrm{mg} / \mathrm{kg}$ do extrato aquoso da Hyptis pectinata pelo mesmo período de tempo. Todos os animais foram sacrificados 24 horas após o procedimento cirúrgico. A regeneração foi analisada através do método de imuno-histoquímica PCNA, usando o anticorpo monoclonal PC-10. Resultados - O índice de regeneração hepática estava significativamente elevado no grupo HP100 $(\mathrm{p}<0,05)$. Conclusões - O presente estudo mostra que o extrato aquoso das folhas da Hyptis pectinata pode estimular a regeneração hepática na concentração de $100 \mathrm{mg} / \mathrm{kg}$. Disponível em URL: http://www.scielo.br/acb

Descritores - Regeneração hepática; Hyptis pectinata; hepatectomia parcial; planta medicinal.

\begin{abstract}
Objective - The use of medicinal plants has increased worldwide. Therefore, it is necessary to know their possible effects in order to establish their correct use on human beings. Taking it into account, the objective of this study was to assess the effects of the aqueous extract of Hyptis pectinata leaves, popularly known as "sambacaitá" or "canudinho", on liver regeneration after partial hepatectomy in rats. Methods - Ten rats were divided into 2 groups: HP group, which underwent $67 \%$ hepatectomy after 4 days of distilled water administration; and HP100 group, which was submitted to partial hepatectomy and oral administration of $100 \mathrm{mg} / \mathrm{kg}$ of the aqueous extract of Hyptis pectinata for the same period of time. All animals were sacrificed
\end{abstract}

1 Trabalho realizado no Departamento de Fisiologia da UFS e no Laboratório de Cirurgia Experimental da FMRP-USP.

2 Acadêmica da Faculdade de Medicina-UFS, bolsista do PIBIC/CNPq-UFS

3 Acadêmico da Faculdade de Medicina-UFS, bolsista do PIBIC/CNPq-UFS

4 Professor Adjunto do Departamento de Fisiologia-UFS

5 Professor Doutor do Depto de Cirurgia e Anatomia da FMRP-USP

6 Professor Titular do Depto de Patologia da FMRP-USP

7 Professor Associado do Departamento de Cirurgia e Anatomia da Faculdade de Medicina de Ribeirão Preto-USP 
24 hours after the surgical procedure. Liver regeneration was evaluated by immunohistochemical staining for proliferating cell nuclear antigen (PCNA) using the PC10 monoclonal antibody. Results - The hepatic regeneration index was significantly increased in HP100 group $(\mathrm{p}<0.05)$. Conclusions - The present study shows that the aqueous extract of Hyptis pectinata leaves can stimulate liver regeneration at $100 \mathrm{mg} / \mathrm{kg}$.

Key words - Liver regeneration; Partial hepatectomy; Hyptis pectinata; medicinal plant.

\section{INTRODUÇÃO}

Nas últimas décadas, a utilização de plantas medicinais como opção de tratamento e cura tem aumentado em todas as classes sociais das mais diversas regiões do mundo. Sabe-se que $80 \%$ da população do planeta já fizeram uso de algum tipo de erva, sendo $30 \%$ por indicação médica ${ }^{1}$.

A Organização Mundial de Saúde recomenda o uso de fitoterápicos como forma de reduzir os custos dos programas de saúde pública, provendo mais fácil acesso para a população mais pobre, em especial nos países em desenvolvimento e subdesenvolvidos ${ }^{2}$.

No Brasil, o uso de ervas medicinais é bastante tradicional e amplo. E, a cada dia, tem se tornado mais comum devido à disseminação da moda naturalista $\mathrm{e}$ ao alto custo dos produtos farmacêuticos industrializados.

O país tem uma flora extremamente rica, com cerca de 55 mil espécies vegetais catalogadas, sendo que 10 mil podem ser consideradas medicinais, aromáticas e úteis ${ }^{3,4}$. Entretanto, faltam trabalhos científicos que comprovem a eficácia no tratamento das enfermidades e recursos para poder isolar os compostos ativos das substâncias estudadas e transformá-los em medicamentos.

A Hyptis pectinata (L.) Poit é uma erva da família Lamiaceae, popularmente conhecida no Brasil como "sambacaitá" ou "canudinho". É uma planta herbácea com folhas aromáticas e com linhas cruzadas. As flores são pequenas, agrupadas em inflorescências, hermafroditas, pentâmeras, zigomorfas e bilabiadas.

Seu uso na medicina popular se dá em inúmeras situações, entre elas: rinofaringite, congestão nasal e doenças de pele ${ }^{5}$, problemas gástricos e febre ${ }^{6}$; infecções bacterianas e fúngicas 7 . Em Sergipe, além do que foi citado, é utilizada na inflamação, na dor e cicatrização de feridas. Os efeitos antiedematogênico e antinociceptivo foram comprovados a partir de seu extrato aquoso ${ }^{8}$. Também foi comprovado seu efeito hepatoprotetor após hepatectomia parcial ${ }^{9}$.
O óleo essencial da Hyptis pectinata contém 33 compostos, com predominância de monoterpenos $(95,8 \%)$. Os principais constituintes são "?-cymene", timol e ß-terpineno. Juntos, correspondem a $68 \%$ do total da planta. Provavelmente, a propriedade anti-séptica é exercida pelo timol ${ }^{5}$.

Diante do exposto, neste trabalho se propôs a avaliar o efeito do extrato aquoso bruto das folhas da Hyptis pectinata sobre a capacidade regenerativa do fígado após hepatectomia parcial.

\section{MÉTODOS}

\section{A - Coleta da planta e preparo do extrato bruto aquoso}

As folhas da Hyptis pectinata foram colhidas na horta de plantas medicinais do Campus da UFS e, depois de separadas, foram secas em estufa com circulação e renovação de ar quente (modelo MA-037) a $37^{\circ} \mathrm{C}$ até completa desidratação.

Elas foram pesadas, trituradas em moinho elétrico até que um pó de fina granulação fosse obtido. O extrato foi feito a partir do pó, acrescentando-se água destilada $(3: 10, \mathrm{p} / \mathrm{v})$ sob agitação constante por 4 horas a $35^{\circ} \mathrm{C}$. Em seguida, foi filtrado $(\mathrm{pH}=6,0)$, liofilizado e armazenado a $5^{\circ} \mathrm{C}$. No momento do uso, o extrato foi dissolvido em água destilada nas concentrações desejadas.

\section{B - Animais}

Utilizaram-se 10 ratos da raça Wistar, machos, pesando entre $180 \mathrm{e} 250 \mathrm{~g}$. Os animais foram mantidos em biotério, com ciclo de claro-escuro natural, temperatura e umidade próprios do ambiente e alimentados com ração e água ad libitum. Extratos de Hyptis pectinata foram administrados durante os 4 dias antecedentes à cirurgia, constituindo o estudo do efeito agudo das folhas da planta.

Os animais foram divididos em 2 grupos:

- Grupo HP (hepatectomia - controle): constituído por 5 animais submetidos à hepatectomia parcial e administração oral de água uma vez ao dia.

- Grupo HP100: constituído por 5 animais submetidos à hepatectomia parcial e administração oral de $100 \mathrm{mg} / \mathrm{kg}$ de extrato aquoso bruto de Hyptis pectinata nos 4 dias antecedentes à cirurgia.

\section{C - Procedimento cirúrgico}

Os procedimentos cirúrgicos foram realizados sempre no mesmo horário, para evitar influência das 
variações do ciclo circadiano. $\mathrm{O}$ anestésico utilizado foi o éter etílico devido a sua praticidade, pelo fato de não possuir potencial hepatotóxico, como gases anestésicos halogenados, e não induzir o metabolismo de drogas ao nível do sistema microssomial hepático, como os barbitúricos ${ }^{10}$. Utilizou-se polivilpirrolidonaiodo na anti-sepsia da parede abdominal após sua tricotomia.

$\mathrm{O}$ acesso à cavidade peritoneal foi feito a partir de laparotomia mediana de cerca de $4 \mathrm{~cm}$ do apêndice xifóide em direção caudal. Em seguida, realizou-se a hepatectomia parcial, ressecando-se os lobos lateral esquerdo e mediano e fazendo ligadura de seus pedículos com fio de algodão 3-0. Essa ressecção equivale a aproximadamente $67 \%$ do volume do fígado ${ }^{11}$. A parede abdominal foi fechada com suturas contínuas de mononáilon 4-0, deixando o peritônio e a aponeurose num plano profundo e a pele, num plano superficial.

Os animais foram submetidos a nova laparotomia para retirada do remanescente hepático após 24 horas. Utilizou-se a mesma técnica anestésica. Posteriormente, foram sacrificados.

\section{D - Método de análise da regeneração hepática}

A técnica de imuno-histoquímica PCNA foi realizada através do uso do anticorpo monoclonal primário anti-PCNA (PC-10; DAKO A/S, Glostrup,
Dinamarca). Os fígados foram fixados em formalina $10 \%$ e embebidos em parafina. Pedaços foram cortados a $4 \mu \mathrm{m}$ e colocados em lâminas revestidas de poli-Llisina, desparafinados, reidratados em séries de álcool, colocados em PBS e tratados com peróxido de hidrogênio $2 \%$, em metanol, por 15 minutos para bloquear a atividade endógena da peroxidase. A coloração imunohistoquímica foi feita pelo método peroxidase-antiperoxidase e a técnica do complexo avidina-biotina. Diaminobenzidina foi usada como substrato cromogênico $^{12,13}$.

As lâminas foram analisadas em microscópios com aumento de 400X e 20 campos foram escolhidos aleatoriamente. Os índices de rotulação nuclear para PCNA foram feitos a partir da contagem de, pelo menos, 1000 hepatócitos.

\section{E - Análise estatística dos dados}

A análise dos dados foi realizada utilizando-se o software de análise estatística SPSS. Foi feita estatística descritiva bem como o teste de Mann-Whitney para comparação dos grupos.

\section{RESULTADOS}

Os resultados do estudo da regeneração hepática por imuno-histoquímica (PCNA) estão apresentados no Figura 1 e na Tabela 1.

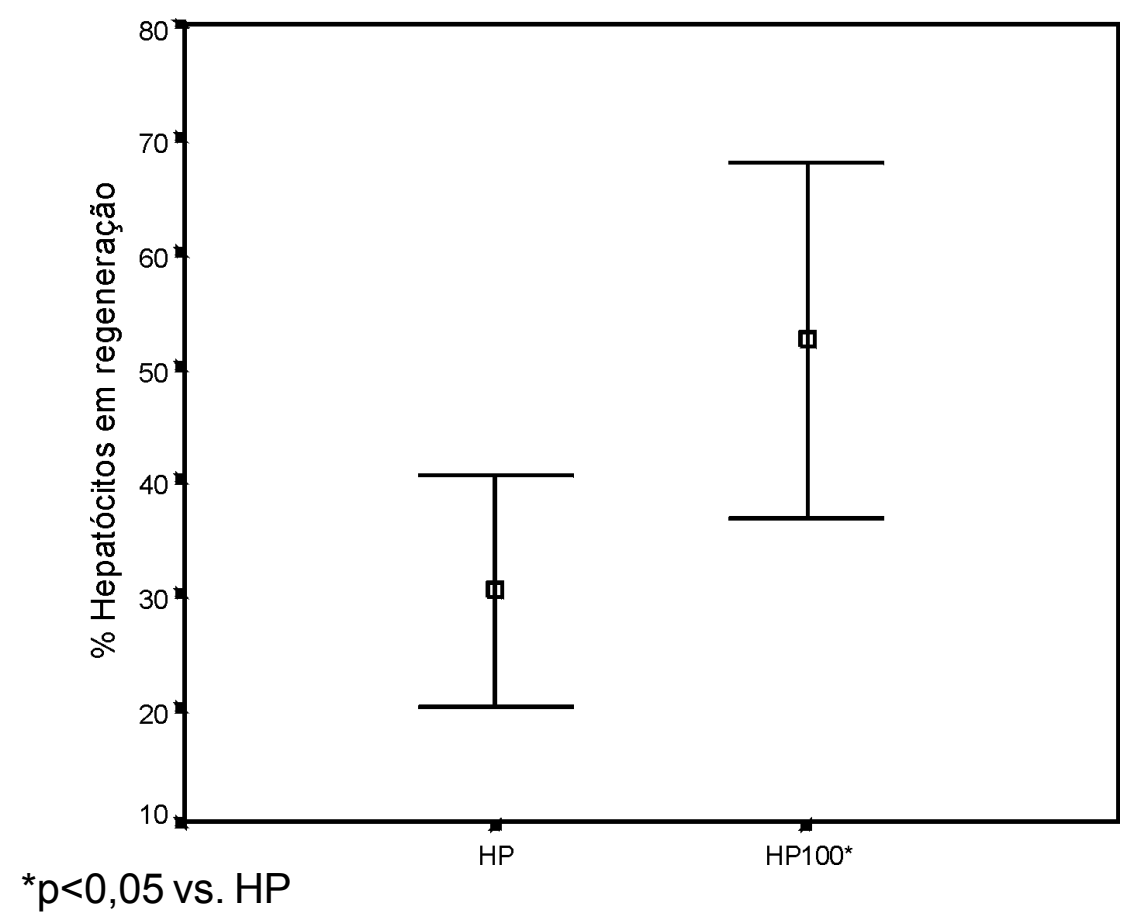

Figura 1 - Índice de regeneração hepática 
Tabela 1 - Resultados individuais da regeneração hepática, mostrando a percentagem de hepatócitos em divisão

\begin{tabular}{ccc}
\hline & HP & HP100 \\
\hline Rato 1 & $38 \%$ & $64 \%$ \\
Rato 2 & $22 \%$ & $39,6 \%$ \\
Rato 3 & $40 \%$ & $64 \%$ \\
Rato 4 & $24 \%$ & $38,6 \%$ \\
Rato 5 & $27,2 \%$ & $55,2 \%$ \\
\hline Total & $30,24 \pm 8,2$ & $52,28 \pm 12,6$ \\
\hline
\end{tabular}

O grupo HP100 apresentou diferença estatisticamente significativa quando comparado com o grupo HP (controle), com $\mathrm{p}=0,028$.

\section{DISCUSSÃO}

De acordo com a Mitologia Grega, Prometeu roubou dos deuses do Olimpo o segredo do fogo e o deu aos homens. Por isso, foi castigado por Zeus a ter seu fígado devorado diariamente por uma águia. No entanto, durante a noite, ele se regenerava, provendo à águia incessante alimentação.

Portanto, é de longa data que se reconhece a existência do processo de regeneração hepática. Mais recentemente, o interesse por elucidar todos os seus mecanismos se tornou bastante eminente. Nesse sentido, tentou-se, neste trabalho, observar o efeito do "sambacaitá" sobre a regeneração do fígado. Sabendo que, em Sergipe, essa planta é empiricamente utilizada como cicatrizante em feridas, acreditava-se a priori que, de alguma maneira, ela pudesse ser capaz de estimular os fatores de crescimento epidérmico, entre eles o EGF ("epidermal growth factor").

Está cientificamente comprovado que o EGF exerce efeitos estimulantes sobre a regeneração hepática ${ }^{14}$. Nos hepatócitos em divisão, foi mostrado que há elevada concentração de receptores desse fator na membrana e no núcleo celular. Sua atuação é sinérgica com a insulina e com o IGF-1 ("insulin-like growing factor"), aumentando a síntese de DNA ${ }^{15}$. Também há indícios de que possa inibir a apoptose ${ }^{16}$.

Um outro mecanismo de ação da Hyptis pectinata a ser considerado é o já comprovado efeito antiinflamatório ${ }^{8}$. Foi mostrado que o extrato aquoso de suas folhas pode atuar como inibidor da ciclooxigenase, além de atuar positivamente sobre receptores opióides. Sabe-se que vários fatores inflamatórios, como o TNF-alfa (tumor necrosis factor - alpha) e a bradicinina, atuam favorecendo a proliferação das células hepatocitárias. Assim, poder-se-ia esperar que o "sambacaitá" inibisse a regeneração hepática por sua ação anti-inflamatória. Entretanto, essa ação só foi significante com concentrações acima de $300 \mathrm{mg} / \mathrm{kg}$. Conseqüentemente, esse mecanismo parece não estar relacionado ao aumento da regeneração na concentração de $100 \mathrm{mg} / \mathrm{kg}$.

Diante do exposto, os mecanismos de ação e as substâncias responsáveis por eles não puderam ser estabelecidas com este trabalho. Mais estudos são necessários para que se possa esclarecer a atuação da planta sobre a regeneração hepática.

\section{CONCLUSÃO}

Conclui-se que a administração durante 4 dias do extrato aquoso bruto liofilizado das folhas da Hyptis pectinata, na concentração de $100 \mathrm{mg} / \mathrm{kg}$ de animal, exerce significativo efeito estimulante sobre a regeneração do fígado após hepatectomia parcial de $67 \%$ em ratos.

\section{AGRADECIMENTOS}

Este trabalho foi financiado com bolsas de iniciação científica do $\mathrm{PIBIC/CNPq} / \mathrm{UFS}$ e projeto Temático FAPESP, proc:.96/01560-2.

\section{REFERÊNCIAS}

1. Castro DM, Castellani DC, Martins ER, Dias JE. Plantas Medicinais. Viçosa: Editora UFV. 2000.

2. Matos FJA. Plantas Medicinais - Guia de Seleção e Emprego de Plantas Medicinais do Nordeste do Brasil. Fortaleza: Editora UFC. 1989.

3. Barata LES, Queiroz SRR. Contribuição efetiva ou potencial do Programa de Apoio ao Desenvolvimento Científico e Tecnológico (PADCT) para o aproveitamento econômico sustentável da biodiversidade. Campinas: [s.n.]. 1995.

4. Ferreira SH. Medicamentos a partir de plantas medicinais no Brasil. Rio de Janeiro: Academia Brasileira de Ciências. 1998.

5. Malan K, Pelissier Y, Marion C, Blaise A, Bessiere JM. The essential oil of Hyptis pectinata. Planta Med 1988;54(6: 531-2. 
6. Martinez M. Las Plantas Medicinales de México. México: Editorial Botas. 1989.

7. Rojas A, Hernandez L, Pereda-Miranda R, Mata R. Screening for antimicrobial activity of crude drug extracts and pure natural products from Mexican medicinal plants. J Ethnopharmaco 1 1992;35(3):275-83.

8. Bispo MD, Mourão RHV, Franzotti EM, Bomfim KBR, Arrigoni-Blank MF, Moreno MPN, Marchioro M, Antoniolli AR. Antinociceptive and antiedematogenic effects of the aqueous extract of Hyptis pectinata leaves in experimental animals. J Ethnopharmacol 2001;76(1):81-6.

9. Melo GB, Silva RL, Antoniolli AR, Melo VA, Lima SO, Silva PM, Castro e Silva Júnior O. Efeitos do extrato aquoso da Hyptis pectinata sobre a regeneração hepática após hepatectomia parcial de $70 \%$. Resultados preliminares. Acta Cir Brás 2001;16 (supl 1): 13-5. Disponível em URL: http:// www.scielo.br/acb

10. Bertelli MSB. Toxicidade do acetominofen em ratos submetidos à hepatectomia parcial. [Dissertação - Mestrado]. Fundação Faculdade Federal de Ciências Médicas de Porto Alegre. 1993.

11. Higgins GM, Anderson RM. Experimental pathology of the liver: restoration of liver of the white rat following partial surgical removal. Arch Pathol 1931;12:186-202.

12. Ramalho FS, Ramalho LNZ, Castro-e-Silva Júnior O, Zuculoto S, Corrêa FMA. Angiotensin-converting enzyme inhibition by lisinopril enhances liver regeneration in rats. Braz $\mathrm{J}$ Med Biol Res 2001;34(1):125-7.
13. Assy N, Gong Y, Zhang M, Pettigrew NM, Pashniak D, Minuk GY. Use of proliferating cell nuclear antigen as a marker of liver regeneration after partial hepatectomy in rats. J Lab Clin Med 1998;131(3):251-6.

14. Gorla Junior JA, Fagundes DJ, Parra OM, Zaia CTBV, Bandeira COP. Fatores hepatotróficos e regeneração hepática. Parte II: fatores de crescimento. Acta Cir Bras [serial online]. 2001; 16(4).

15. Hashimoto M, Kothary PC, Eckhauser FE, Raper Steven E. Treatment of cirrhotic rats with epidermal growth factor and insulin accelerates liver DNA synthesis after partial hepatectomy. J Gastroenterol Hepatol 1998;13(12):1259-65.

16. Roberts RA, James NH, Cosulich SC. The role of protein kinase $\mathrm{B}$ and mitogen-activated protein kinase in epidermal growth factor and tumor necrosis factor alpha-mediated rat hepatocyte survival and apoptosis. Hepatology 2000;31(2):420-7.

\section{Endereço para Correspondência}

\section{Orlando de Castro e Silva Jr}

Departamento de Cirurgia e Anatomia

Faculdade de Medicina de Ribeirão Preto - USP

Campus Universitário - Monte Alegre

14049-990 - Ribeirão Preto - SP

e-mail-orlandocjs@hotmail.com

Conflito de interesse: nenhum

Fonte de Financiamento: FAPESP 